\title{
Porewater nutrient fluxes in a shallow fetch-limited estuary
}

\author{
C. E. Oldham ${ }^{1, *}$, P. S. Lavery ${ }^{2}$ \\ ${ }^{1}$ Centre for Water Research, The University of Western Australia, Nedlands, Western Australia 6907, Australia \\ ${ }^{2}$ Centre for Ecosystem Management and School of Natural Sciences, Edith Cowan University, Joondalup. \\ Western Australia 6027, Australia
}

\begin{abstract}
The Swan River Estuary is a shallow meso-eutrophic system in SW Australia. The dominant summer wind pattern in the region includes a strong SW sea breeze each afternoon. We hypothesised that such a regular and significant wind event may be important in causing the release of sediment porewater with subsequent effects on water quality and nutrient dynamics. To test this, we conducted a multidisciplinary field experiment in 1996 during which we measured temperature microstructure profiles (to yield turbulence parameters), velocity profiles, light profiles and nutrient profiles. Bottom shear stresses were estimated via the viscous-dissipation method, which can be used in stratified and unstratified water bodies or during convective cooling, all of which are likely to affect sediment-water dynamics in shallow systems. We observed that, after the sea breeze began, there was a dramatic breakdown of temperature stratification, an increase in mean velocities and an increase in turbulence levels at the sediment-water interface. This coincided with a doubling of water column ammonium concentrations. However, this pulse of nutrients was shown to occur prior to conditions necessary for sediment resuspension. We therefore attribute the increased porewater fluxes to interactions between increasingly energetic hydrodynamics and the benthic environment. The technique used here to measure porewater fluxes as a function of hydrodynamic forcing is an excellent alternative to benthic chamber experiments, which isolate the sediments from the overlying hydrodynamics.
\end{abstract}

KEY WORDS: Porewater fluxes · Resuspension - Subtidal pumping - Ammonium

\section{INTRODUCTION}

Porewater fluxes are typically significant mechanisms of internal loading of contaminants to an aquatic system. These fluxes will be driven by diffusion (Jørgensen \& Revsbech 1985), advection (Riedl et al. 1972 ) or sediment resuspension (Søndergaard et al. 1992). These 3 processes will be affected by the hydrodynamics alone or by interactions between the hydrodynamics and the local hydrology (Simmons 1992) and benthic organism activity or bioroughness (Huettel \& Gust 1992).

The major hydrodynamic processes likely to affect porewater fluxes are: mean currents due to tides, inflows or convection; oscillating currents due to sur-

•E-mail: oldham@cwr.uwa.edu.au face waves; and intermittent velocities due to turbulent eddies close to the benthic boundary. In addition, density stratification may modify the effects of each of these processes. Benthic organism activities which, when superimposed on the overlying hydrodynamics, are most likely to affect porewater fluxes include bioturbation with the resulting direct irrigation (Aller 1984) and also the establishment of roughness elements, such as mounds, on the surface sediment (Huettel \& Gust 1992).

Hammond et al. (1985) summarise 4 methods for determining porewater fluxes: firstly, through the collection of sediment cores, followed by incubation in the laboratory and measurement of chemical concentrations in the overlying water; secondly, through the measurement of porewater profiles in the sediment and subsequent calculation of chemical fluxes. Draw- 
backs of both of these methods are the assumption that diffusive fluxes dominate and also the assumption of process homogeneity which is necessary when applying the results to whole systems. The third method described by Hammond et al. (1985) is the use of benthic chambers. The main drawbacks of this method are the isolation of the chambers' internal waters from the surrounding physical forcing, and the possibility that the chambers may themselves create experimental artefacts (Glud et al. 1996). In order to overcome the hydrodynamic isolation, some benthic chambers have flexible tops which allow the transfer of momentum from surface wave action into the chamber (Malan \& McLachlan 1991). The final method described by Hammond et al. (1985) is the measurement of changes in chemical concentrations in waters adjacent to the sediment (without the use of chambers). Though problematic because of the risk of being unable to detect chemicals released from the sediment, this method has the distinct advantage of the sediment experiencing the full hydrodynamic forcing, and also of integrating fluxes over a large area.

With the above in mind, a multidisciplinary field experiment was completed in February 1996 in Perth, Western Australia, on the Swan River Estuary. The Swan Coastal Plain in SW Australia is subject to a highly predictable daily wind pattern during summer. This pattern consists of a strong easterly land breeze in the morning, a midday calm, a strong south-westerly sea breeze in the afternoon and finally a nighttime calm (Masselink 1996). Water bodies in the region also experience intense solar heating of surface waters during the midday calm, when air temperatures may reach $40^{\circ} \mathrm{C}$, resulting in strong vertical stratification (MacIntyre 1993). By late afternoon the sea breeze is often sufficiently strong to cause mixing of the water column. Such afternoon mixing is observed wherever the fetch does not limit the effects of the south-westerly winds (Gabrielson \& Lukatelich 1985). It has previously been observed that these meteorological conditions typically induce a dramatic increase in bottom sediment resuspension in nearshore areas (Masselink \& Pattiaratchi 1998).

Like any other shallow estuary experiencing regular wind patterns, the daily sea breeze typically breaks down the diel stratification, increases wave and current activity, increases bottom turbulence and therefore increases total physical forcing on the bottom sediments. We therefore hypothesised that porewater fluxes are temporally variable, responding to these changes in physical forcing at the sediments. This paper describes the experiment conducted to establish the viability of using direct nutrient concentration measurements in the overlying water column to estimate the temporal variability of porewater fluxes.

\section{METHODS}

Study site. The Swan River Estuary (Western Australia) is permanently open to the Indian Ocean at the City of Fremantle and extends $60 \mathrm{~km}$ inland through the City of Perth to its confluence with the Avon and Helena Rivers. The estuary is generally shallow $(<3 \mathrm{~m})$ with occasional channels dredged to $17 \mathrm{~m}$ depth. The estuary has been classified as seasonal because river flow ceases during summer, when it is marine along its full length and flushing is dominated by tidal exchange. The average tidal oscillation in less than $0.5 \mathrm{~m}$.

We conducted experiments on Armstrong Bank $\left(32^{\circ} 00^{\prime} 15^{\prime \prime} \mathrm{S}, 115^{\circ} 48^{\prime} 30^{\prime \prime} \mathrm{E}\right.$ ) in Melville Water (Fig. 1). The bank is composed of medium ( $0.3 \mathrm{~mm})$ quartz sands and at its most shallow point is less than $1 \mathrm{~m}$ deep, dropping sharply into water of $12 \mathrm{~m}$ depth. Armstrong Bank is exposed to the afternoon sea breezes and the morning easterly land breezes with fetches of $3 \mathrm{~km}$ in both directions. We established a shallow site (Site A) on top of the bank in water at 1 to $1.3 \mathrm{~m}$ depth. and a deep site (Site B) at 3 to $3.3 \mathrm{~m}$ depth. The sites were within $50 \mathrm{~m}$ of each other and both within $200 \mathrm{~m}$ of the shore.

Bottom shear stresses. In order to characterise the physical forcing at the sediments, we must estimate the shear stress, $\tau$, at the bottom boundary. Estimation of bottom stresses is possible via 4 methods. Huntley (1988) describes 3 methods: the 'mean flow method', where benthic shear stresses are related to the mean flow assuming a logarithmic velocity profile above the bottom boundary (e.g. Grant \& Madsen 1979); the 'eddy correlation method', where horizontal and vertical velocity fluctuations are directly measured, therefore allowing calculation of the Reynolds stress, turbu-

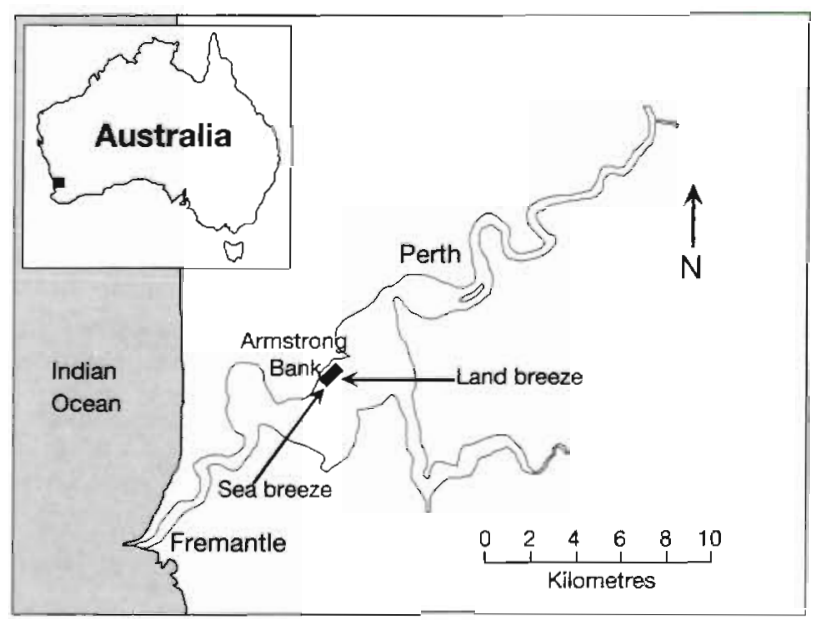

Fig. 1. Study site on the Swan River Estuary in Western Australia. The estuary, which opens to the Indian Ocean, has an average depth of $2 \mathrm{~m}$ with tidal oscillations of less that $0.5 \mathrm{~m}$ 
lent momentum flux and thus bottom stress (e.g. Grant et al. 1984); and the 'inertial dissipation method', where the rate of dissipation of turbulent kinetic energy $(\varepsilon)$ is estimated from the inertial sub-range of the universal turbulence velocity spectrum, and the bottom stress is then related to the dissipation (e.g Huntley 1988). The fourth method, which we will term the 'viscous-dissipation method', estimates the dissipation from the viscous-convective sub-range of the universal turbulence spectra and then relates bottom stresses to dissipation.

Disadvantages of the first 3 methods are also discussed by Huntley (1988). The mean flow method requires accurate simultaneous velocity and height measurements within the logarithmic layer, making the method very sensitive to sensor drift, especially in low flow conditions. The eddy correlation method is extremely sensitive to errors in alignment of the sensor axes. The inertial dissipation method is dependent on a well-defined inertial sub-range. This will only occur for sufficiently high Reynolds numbers. These high turbulence Reynolds numbers are rarely observed in natural water bodies outside the highly energetic surface boundary layer (Terray et al. 1996).

Methods for estimating dissipation from the viscousconvective (or microstructure) sub-range of turbulence spectra were first described by Dillon \& Caldwell (1980). They used temperature as a turbulent scalar, which is not subject to sensor alignment error, but which still exhibits the universal turbulence spectra as initially described by Batchelor (1959). Since then, temperature microstructure profilers have been extensively used to estimate dissipation in the ocean (e.g. Mack 1985) and in lakes (e.g. Imberger \& Ivey 1991).

In the field experiment described in this paper, we used a profiler to collect temperature microstructure profiles at both shallow and deep sites. The profiler descended through the water column until a weightrelease switch was activated at the required depth and sampling began. The profiler sampled at $100 \mathrm{~Hz}$ and ascended the water column at $10 \mathrm{~cm} \mathrm{~s}^{-1}$, giving a spatial resolution of $\cong 1 \mathrm{~mm}$ for temperature and conductivity. The profiler was identical to that described by Oldham (1994) but without the dissolved oxygen sensor. The method for the estimation of dissipation from the temperature gradient spectra is described in Imberger \& Ivey (1991).

These dissipation estimates must then be related to bottom stresses. Fredsoe \& Deigaard (1994) used Prandtl's mixing length theory to relate shear stresses at the bottom boundary to turbulent eddy characteristics:

$$
\tau=\rho l q \frac{\mathrm{d} u}{\mathrm{~d} z}
$$

where $l$ is the characteristic length scale, $q$ the characteristic velocity scale of a turbulent eddy and $\rho$ the water density. Also, fluid contained within a turbulent eddy will be transported the distance, 1 , and will experience a characteristic velocity, $q$, where

$$
q \cong l \frac{\mathrm{d} u}{\mathrm{~d} z}
$$

Thus, substituting Eq. (2) into Eq. (1) gives us

$$
\tau=\rho q^{2}
$$

Since $\tau=\rho u_{.}^{2}$, where $u$. is the shear velocity at the bottom boundary, this shows that $q$ and $u$. are equivalent. In order to close this calculation we now require a relationship between the characteristic velocity scale, $q$, and the dissipation, $\varepsilon$.

Ivey \& Imberger (1991) showed that the root mean square velocity of turbulent motions, equivalent to $q$ above, is correlated with the dissipation and a characteristic length scale of eddies. This characteristic length scale, equivalent to $l$ above, is known as the centred displacement scale, $L_{\mathrm{c}}$ and is calculated from monotonising the density via a bubble-sorting algorithm. The modulus of the distance a fluid particle is moved during the density monotonising routine gives an indication of the displacement scale, as described by Imberger \& Boashash (1986). The relationship between the velocity scale and dissipation is given by Ivey \& Imberger (1991) as

$$
q=2\left(\varepsilon L_{c}\right)^{1 / 3}-u_{c}
$$

where $u_{c}=0.05 \mathrm{~m} \mathrm{~s}^{-1}$

Thus, we can fully characterise the mean bottom shear stresses as

$$
\tau=\rho\left[2\left(\varepsilon L_{c}\right)^{1 / 3}-u_{c}\right]^{2}
$$

Calculation of mean shear stresses via the viscousdissipation method does not require any assumptions regarding the hydrodynamics. The method holds for stratified and non-stratified water bodies, as well as during periods of convective cooling. It also requires no assumptions regarding the interaction of waves and currents. As such it is a powerful tool for quantifying mean shear stresses experienced by the bottom sediments.

Wind. Wind speed and direction sensors were logged every $10 \mathrm{~min}$ at the deep site, $2.5 \mathrm{~m}$ above the water. The wind speeds were later corrected to $U_{10}$, the wind speed at $10 \mathrm{~m}$ above the water surface, assuming a logarithmic velocity profile (roughness $z_{0}$ $=0.01 \mathrm{~m}$ ). Wind data were collected from February 12 to $16,1996$.

Water column nutrients. Water column nutrient concentrations were profiled on February 14 and 15 , 1996 at irregular intervals between 08:15 and 18:00 h. A continuous water quality sampling pump was used to collect water column samples for nutrient analysis. The sampler comprises a constant velocity peristaltic 
pump (Masterflex ${ }^{\mathrm{TM}}$ ) with opaque (silicon) tubing and a flattened intake nozzle to allow samples to be withdrawn from discrete depths of $1 \mathrm{~cm}$. The sampling nozzle was fitted with a depth sensor providing real time information on the depth $( \pm 0.01 \mathrm{~m})$ of the sampling nozzle

Samples were collected through the water column before, during and after the sea breeze events for later analysis of soluble nutrients. Samples were analysed for nitrate+nitrite- $N$ (hereafter referred to as nitrate-N), ammonium- $N$ and filterable reactive phosphorus (FRP) using standard methods 4500-NO3 -F (cadmium-reduction), 4500-NH3 -H (phenate) and 4500-P -F (ascorbic acid) respectively as per APHA (1989). Samples were collected within $0.5 \mathrm{~m}$ of the surface, $0.3 \mathrm{~m}$ of the bottom and at 1 intermediate depth at the shallow site and 2 intermediate depths at the deep site.

Water column samples which did not require filtering were pumped directly from the water column into opaque sample storage bottles. Samples which required filtering before chemical analysis were filtered on board the research vessel. All samples were stored on ice then frozen within $2 \mathrm{~h}$ of collection prior to chemical analysis.

Porewater nutrients. Ten replicate intact sediment cores were collected from each site to determine porewater nutrient concentrations. The sediments were collected in $4.5 \mathrm{~cm}$ diameter polycarbonate corers inserted to at least $10 \mathrm{~cm}$ depth either by SCUBA divers or from the surface using a Wildco ${ }^{\text {TM }}$ coring apparatus. Sediment cores were returned to the surface and the top $1 \mathrm{~cm}$ sliced off under an air atmosphere if the apparent redox discontinuity (ARD) suggested the sediment was oxic, or under a nitrogen atmosphere if it suggested the sediment was anoxic. The ARD is a visual assessment of the depth of the oxygenated layer in sediments based on the difference in the colour of reduced and oxidised sediments; it has been successfully applied in studies elsewhere (MWRA 1992).

Each sediment slice was transferred directly into a polycarbonate WildcorM sediment squeezer and porewater extracted under 3 atmospheres of pressure provided by either compressed air or compressed nitrogen. Squeeze-water techniques (sensu Bolliger et al. 1992) were employed since they overcame many of the artefacts associated with centrifugation and vacuum filtration and were easily adapted to the field situation. The interstitial water was analysed for FRP, ammonium- $\mathrm{N}$ and nitrate- $\mathrm{N}$ as described above. The sediments proved to be a $0.3 \mathrm{~mm}$ medium quartz sand with a small porewater volume. Consequently the porewater from 2 replicate sediment slices was bulked to provide sufficient volume for analysis.

\section{RESULTS}

\section{Wind}

Wind data for both days were typical of the summer wind pattern for Perth with morning easterly land breezes swinging to strong south-westerly sea breezes in the afternoon. Fig. 2 shows the wind speed, corrected to $U_{10}$, and direction on February 14 and 15 . On February 14, easterly winds slowly dropped from $8 \mathrm{~m}$ $\mathrm{s}^{-1}$ at midnight to around $1 \mathrm{~m} \mathrm{~s}^{-1}$ by $13: 00 \mathrm{~h}$. At that time, a south-westerly sea breeze increased until, from $14: 30$ to $18: 00 \mathrm{~h}$, it averaged $6 \mathrm{~m} \mathrm{~s}^{-1}$. After 18:00 h the wind speed rapidly dropped to close to zero.

On February 15, an easterly wind of up to $9 \mathrm{~m} \mathrm{~s}^{-1}$ occurred during the previous night, but had dropped by 10:00 h. There was minimal wind from 10:00 until 13:00 $\mathrm{h}$, when again a sea breeze began. This westerly wind steadily increased in strength until 17:30 h, when it reached $8 \mathrm{~m} \mathrm{~s}^{-t}$, after which it dropped off.

The main difference that should be noted between the 2 days is the period on February 15 between 10:00 and 13:00 h when there was no wind during the period of maximum solar heating. These conditions were optimal for the creation of strong temperature stratification in the surface waters. On February 14, winds of at least $2 \mathrm{~m} \mathrm{~s}^{-1}$ existed during the period of maximum solar heating, which prevented strong temperature stratification of the water column.

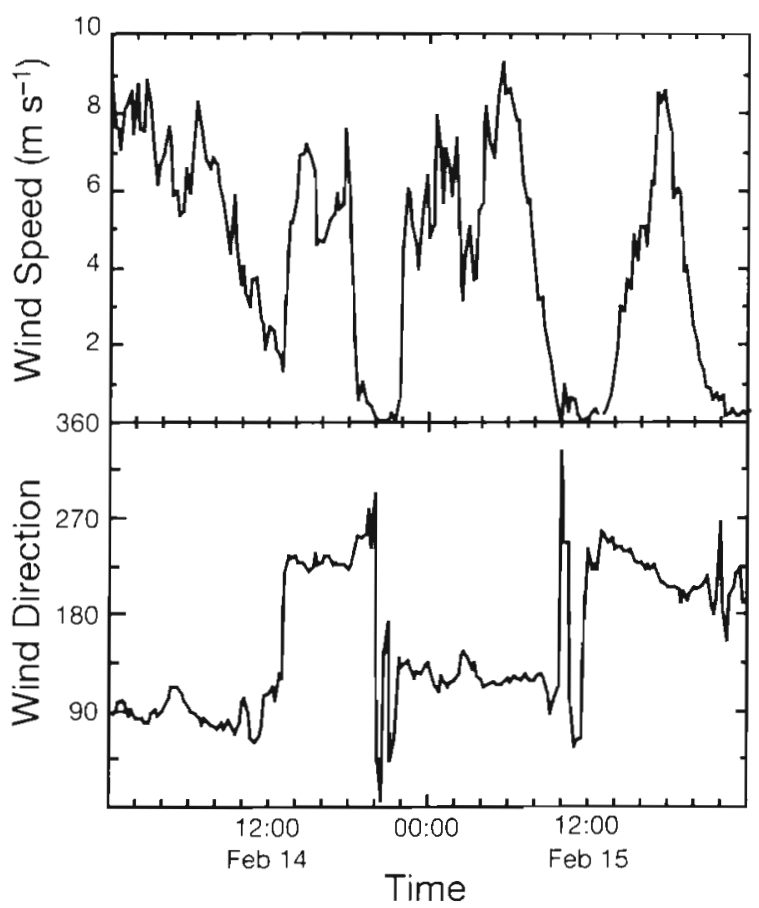

Fig. 2. Wind speed and direction over the $2 \mathrm{~d}$ of intensive field measurements 


\section{Temperature stratification and mixing}

A typical series of temperature microstructure profiles are shown in Fig. 3. The initial profile was collected at 13:38 h on February 15, just before the seabreeze began. The surface $0.5 \mathrm{~m}$ had heated to $28.8^{\circ} \mathrm{C}$, inducing a $1.5^{\circ} \mathrm{C}$ temperature stratification over the water column. The second temperature profile was collected at 14:42 h, when the sea breeze had reached $5 \mathrm{~m} \mathrm{~s}^{-1}$. By this time, the surface layer had deepened to $2.5 \mathrm{~m}$, with an average temperature of $28.1^{\circ} \mathrm{C}$. The third profile was collected at $15: 07 \mathrm{~h}$, by which time the water column was fully mixing, with an average temperature of $28^{\circ} \mathrm{C}$.

Fig. 3 also shows the corresponding temperature gradient profiles, which are used for spectral analysis and dissipation estimates. However, qualitative estimates of the energetics of the water column can be obtained from the magnitude of 2 -sided fluctuations present in the profile. The initial profile at $13: 38 \mathrm{~h}$ shows mixing, indicated by strong 2-sided fluctuations, down to $1 \mathrm{~m}$. Then as the wind increased, the mixing deepened to $3.1 \mathrm{~m}$ at $14: 42 \mathrm{~h}$ and then by $15: 07 \mathrm{~h}$ the water column was fully mixing. Note that as the water column becomes isothermal, i.e. the change in temperature with depth becomes minimal, the magnitude of the 2 -sided fluctuations decreases even though the energetics of the water column has likely increased. Under these circumstances spectral analysis of the temperature gradient signal becomes essential.

February 14 and 15 showed similar trends of increasing temperature stratification around mid-day when the wind dropped, followed by rapid mixing of the water column as the winds increased during the afternoon. However, as expected from the wind data, stronger thermal stratification was observed on February 15.

\section{Porewater nutrients}

The surface $1 \mathrm{~cm}$ of all sediment cores appeared oxic, with the ARD at a depth of $3 \mathrm{~cm}$ or deeper in all cases. Fig. 4 shows that, despite the oxic con- dition of the sediment, the porewater inorganic nitrogen was dominated by ammonium-N, with mean concentrations exceeding $3000 \mu \mathrm{g} \mathrm{I}^{-1}$ compared to less than $500 \mathrm{\mu g} \mathrm{l}^{-1}$ for nitrate-N. Mean FRP concentrations were in the order of 120 to $145 \mu \mathrm{g} \mathrm{l} \mathrm{l}^{-1}$. The relatively low FRP concentrations and high ammonium- $N$ concentrations were reflected in high mean N:P ratios of 33 and 37 at the shallow and deep site respectively. $t$-tests revealed no significant differences in the concentration of porewater nutrients at the deep and shallow sites $\left(\mathrm{p}=0.83\right.$ for FRP, $\mathrm{p}=0.21$ for $\mathrm{NO}_{3}-\mathrm{N}$ and $\mathrm{p}=0.82$ for $\mathrm{NH}_{4}-\mathrm{N}$ ).

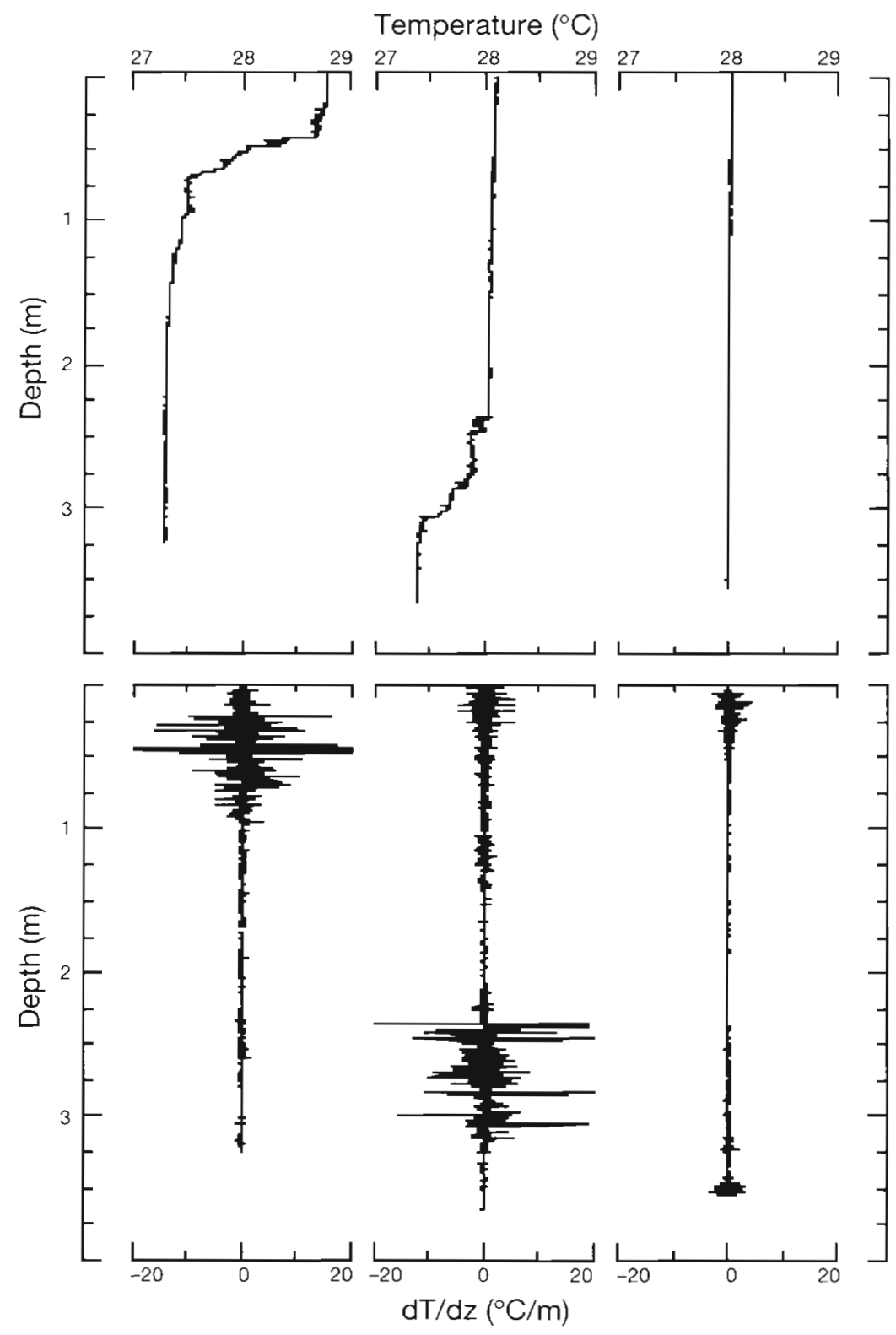

Fig. 3. Examples of temperature microstructure profiles collected on February 15 at (A) 13:38 h, (B) 14:42 h, and (C) 15:07 h. The top panels show temperature profiles and the bottom panels show temperature gradient profiles 


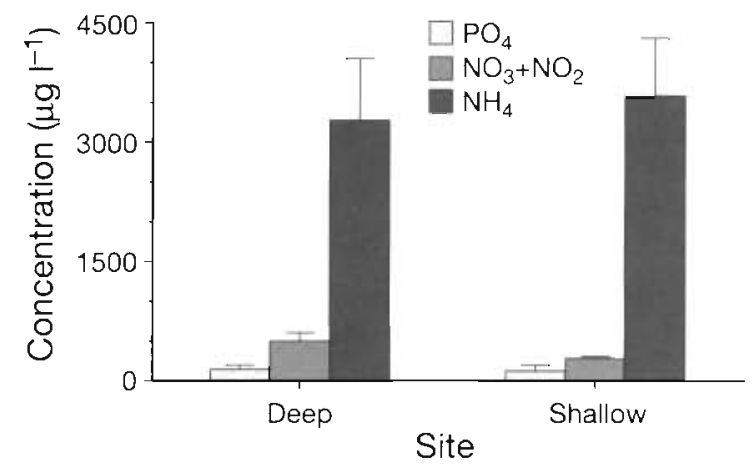

Fig. 4. Porewater nutrient concentrations at both the deep and shallow sites

\section{Water column nutrients}

There were no discernible patterns in water column nitrate-N or FRP concentrations over the 2 days. Nitrate-N concentrations were always less than $2 \mu \mathrm{g}$ $\mathrm{l}^{-1}$. FRP concentrations ranged from 23 to $40 \mathrm{\mu g} \mathrm{l}^{-1}$ over the 2 days. These nutrients were vertically homogeneous with no observable difference between the deep and shallow sites.

In contrast to nitrate- $\mathrm{N}$ and FRP, ammonium- $\mathrm{N}$ concentrations showed periods of both spatial and temporal patchiness. Fig. 5 shows ammonium-N data for February 14 at the deep site. Ammonium-N concentra-

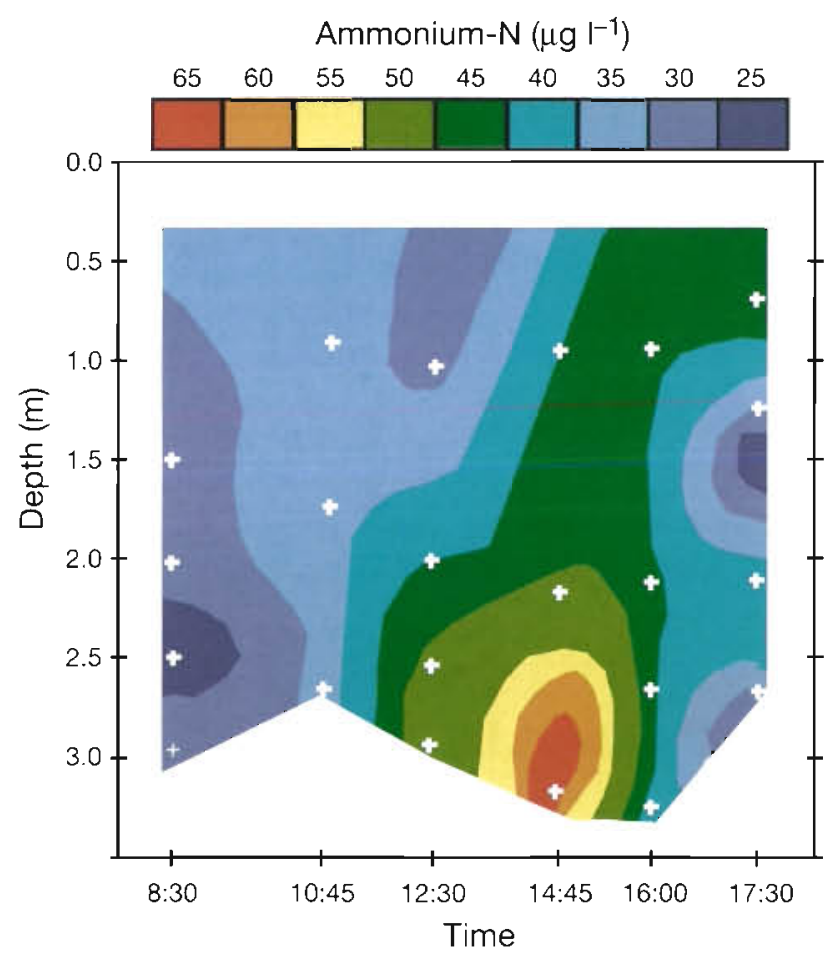

Fig. 5. Concentration contours of ammonium-N $\left(\mu \mathrm{g} \mathrm{l}^{-1}\right)$ in the water column on February 14, at the deep Site B tions were relatively uniform through the water column between about 10:30 and 12:00 h. By 14:45 h, immediately after the onset of the sea breeze (see Fig. 2), there had been a sudden elevation in bottom concentrations of ammonium-N. Fig. 6 shows a similar pattern occurring at the shallow site, but $30 \mathrm{~min}$ earlier. Baseline concentrations of between 30 and $40 \mu \mathrm{gl}^{-1} \mathrm{NH}_{4}-\mathrm{N}$ doubled to over $65 \mathrm{\mu g} \mathrm{l}^{-1}$ at both the shallow and the deep site. Evidence of increased ammonium- $N$ concentrations could be detected until 16:00 h near the bottom sediments, and until 17:30 h at the water surface (Fig. 5).

On February 15, when there was a protracted period of zero wind with maximum solar heating, no pulses of bottom water nutrients were observed before or after the onset of the sea breeze.

\section{DISCUSSION}

\section{Hydrodynamic forcing}

We have measured a range of meteorological and hydrodynamic conditions during our field experiment and must now assess the significance of these conditions for porewater nutrient fluxes. In order to make this assessment we utilise Shields' parameter, a nondimensional number representing the ratio of sediment lifting forces due to shear stresses, to sediment

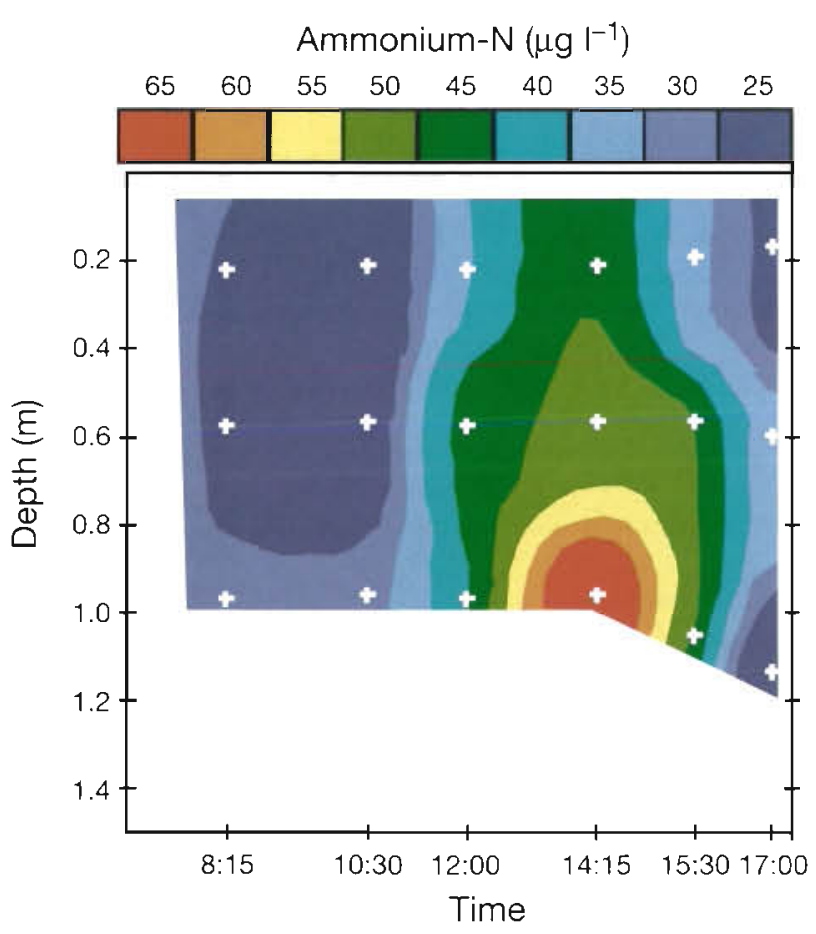

Fig. 6. Concentration contours of ammonium-N $\left(\mu \mathrm{g} \mathrm{I}^{-1}\right)$ in the water column on February 14 , at the shallow Site $A$ 
settling forces due to gravity. Thus, Shields' parameter gives the potential for sediment resuspension which, with the associated porewaters being ejected into the water column, can be considered the upper bound for porewater fluxes. A comparison of porewater fluxes with Shields' parameter will give insights into the dynamics of sediment nutrient exchange as a function of physical forcing.

Shields' parameter, $\theta$, is given by

$$
\theta=\frac{\tau}{\rho(s-1) g D}
$$

where $\tau$ is the mean shear stress (as defined above), $D$ is the mean sediment grain size, $g$ is gravitational acceleration, and $s$ is the relative density

$$
s=\frac{\rho_{\mathrm{s}}}{\rho}
$$

and $\rho_{\mathrm{s}}$ is the density of sediment and $\rho$ is the density of water.

Shields' parameter can be used to determine the potential for sediment resuspension under the applied hydrodynamic forcing. The critical value of Shields' parameter, $\theta_{c,}$ required for sediment resuspension is dependent on the grain Reynolds number, Re.

$$
\mathrm{Re}_{.}=\frac{u_{0} D}{\mathrm{v}}
$$

When $\mathrm{Re}$, is approximately 3 , a smooth boundary flow exists and in this flow regime $\theta_{c}=0.1 \mathrm{Re}^{-1}$ and may have a maximum value of 0.4 . In the regime where $3<\mathrm{Re}$. $<200$ there is a transitional region where there is a minimum value of $\theta_{c}=0.03$. When $\mathrm{Re} .>200, \theta_{c}$ is no longer a function of $\mathrm{Re}$. and remains constant at 0.05 (van Rijn 1985). In the experiment described in this paper, once the sea breeze started, $\operatorname{Re} . \approx 3$; thus we expect $\theta_{c}$ has a minimum value of approximately 0.03 .

Fig. 7 shows Shields' parameters for each microstructure profile measured during the experiment. These Shields' parameter estimates used the mean shear stresses calculated via the viscous-dissipation method described above and therefore are denoted $\theta_{\varepsilon}$. Fig. 7 shows that the only time at which that physical forcing was close to that required for sediment resuspension $\left(\theta_{c} \approx 0.03\right)$ was at $17: 40 \mathrm{~h}$ on February 14 . At no time on February 15 did Shields' parameter exceed 0.03 .

As discussed in the 'Results' section, the major difference between the 2 days of the field experiment occurred between 10:00 and 13:00 h. On February 15, there was a $2 \mathrm{~h}$ lag between the drop off of the easterly land breeze and the onset of the south-westerly sea breeze. This period of minimal wind during maximum solar insolation ensured strong temperature stratification in the surface waters.

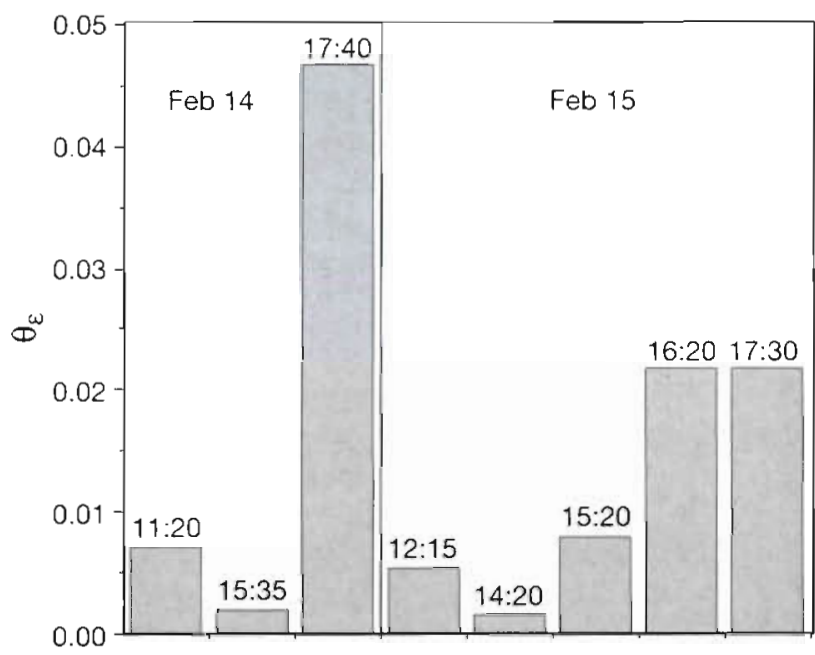

Fig. 7. Shields' parameters calculated using mean shear stresses estimated via the viscous-dissipation method

Surface temperature stratification is an inhibitor to mixing of the water column. Energy imparted by the wind, or by convective cooling, to the water column must initially break down the stratification before that energy can be transferred to the underlying waters (Fischer et al. 1979). Thus, for a given surface forcing, benthic shear stresses following periods of prolonged stratification are likely to be lower than shear stresses on days with minimal stratification. This effect is likely to be ecologically significant for shallow water bodies which undergo daily stratification and destratification.

\section{Timing of porewater seepage}

Given the above details of the physical forcing experienced by the sediments, we note that the pulse of ammonium measured at both sites on February 14 occurred before bottom shear stresses were sufficient to cause resuspension. It should also be noted that no additional pulses were measured once the shear stresses exceeded the critical resuspension value. Thus, detectable nutrient release from the sediments was not coupled to the resuspension of the sediments.

The occurrence of the nutrient pulse prior to sediment resuspension can most likely be explained by either advection of high nutrient water into the study area or by increased porewater fluxes. We discount advection as a likely cause because, firstly, the nutrient pulse appears at the bottom boundary of both sites, i.e. it appeared at $3 \mathrm{~m}$ at the deep site and at $1 \mathrm{~m}$ at the shallow site, and, secondly, it was restricted to within $0.5 \mathrm{~m}$ of the bottom boundary at both sites. Such containment of a hypothetical inflow to the bottom boundary could only be maintained by a density 
differential between the inflow and the ambient water column. Such an inflow-induced density differential was not observed in any of the temperature microstructure profiles.

We therefore conclude that the nutrient pulses were caused by porewater fluxes responding to an increase in benthic shear stresses. The preliminary study presented here is unable to determine the actual cause of the increased fluxes; however, we speculate that interactions between the hydrodynamics and bioroughness, as described by Huettel \& Gust (1992), would be extremely likely given the highly productive benthic environment in this estuary.

\section{Nutrient dynamics}

The dominance of ammonium- $\mathrm{N}$ in the porewaters has been confirmed for other locations and times in the Swan River Estuary (G. Douglas pers. comm., R. Gerritse pers. comm.). Similar observations were reported for the Yarra estuary and Hobson Bay in Eastern Australia (Harris et al. 1996). In these cases it was explained in terms of an absence of nitrification occurring in the sediments due to high organic loading and the subsequent ammonification and oxygen depletion. It is possible that a similar situation is occurring in the Swan River sediments.

The high N:P ratios measured at these sites (about 35:1) was well in excess of the Redfield ratio for phytoplankton derived organic matter (16:1). Often, the N:P ratio of porewater is less than 16:1 due to losses of $\mathrm{N}$ from the organic material through denitrification. The high N:P ratio measured suggests that denitrification is not occurring in these sediments, or that the ammonium is being derived from relatively refractory organic matter which has a high N:P ratio following remineralisation of the more labile portion.

Regardless of the mechanism providing it, the dominance by ammonium of the sediment-water nitrogen exchange is ecologically significant. Ammonium is known to be the preferred source of nitrogen for many algal species (Dugdale \& Goering 1967). In addition, Thompson \& Hosja (1996) have shown that the Swan River Estuary is generally an N-limited estuary in respect to phytoplankton growth. A flux of ammonium-rich porewaters with an average $\mathrm{N}: P$ ratio of 35:1 into the water column is, therefore, likely to be a significant source of nitrogen to $\mathrm{N}$ limited phytoplankton, in a preferred form, and during summer when bioavailable nitrogen concentrations are at their lowest.

Harris et al. (1996) have also commented on the ecological significance of ammonium-dominated porewater fluxes. They point out that the ultimate result of this situation is likely to be a degradation into a eutrophic state as the potential is established for a rapid recycling of ammonium between sediments and phytoplankton in the water column. Given its relatively low tidal exchange, and therefore flushing rate, this scenario must also be considered a possibility for the Swan River Estuary

It should be noted that the absence of nitrate- $\mathrm{N}$ and FRP pulses coincident with $\mathrm{NH}_{4}-\mathrm{N}$ pulses is simply attributed to dilution. Given the lower concentrations of $\mathrm{NO}_{3}-\mathrm{N}$ and FRP in the porewaters compared to $\mathrm{NH}_{4}-\mathrm{N}$, advection and mixing of porewaters into the overlying water column will dilute $\mathrm{NO}_{3}-\mathrm{N}$ and FRP to concentrations below detection limits.

\section{CONCLUSIONS}

This paper presents the first example of the relationship between mean benthic shear stresses, estimated via the viscous-dissipation method, and porewater fluxes. The viscous-dissipation method does not experience the same shortfalls as other methods of estimating mean shear stresses and has been used extensively in both oceanic and limnological research. In particular, this method can be used in stratified and unstratified water bodies, and also during convective cooling All of these conditions will be significant for shallow systems such as the estuary described here.

We considered that sediment resuspension was the upper end point for porewater fluxes and therefore used Shields' parameter to assess the conditions at the benthic boundary. Increased porewater fluxes of ammonium were observed prior to the critical value of Shields' parameter being reached, indicating sediment resuspension had not occurred. The increased porewater fluxes were most likely due to interactions between increasingly energetic hydrodynamics and benthic organism activity.

We have documented ammonium porewater fluxes from 2 adjacent sites under typical summer conditions. We have also shown the viability of using the combination of shear stress estimation and overlying nutrient monitoring to indicate temporal variability in porewater fluxes. Such techniques provide an alternative to benthic chamber experiments, and have the advantage in that they do not isolate the sediments from overlying hydrodynamics. The technique described here also produces benthic flux data which integrates sediment processes, thus allowing assessment of the ecological significance of those fluxes.

Having established the viability of this technique, we now intend to repeat such measurements over longer periods of time to assess the temporal patterns of porewater fluxes under variable forcing conditions. 
Acknowledgements. This study was funded by the Western Australian Estuarine Research Foundation. The study would not have been possible without field assistance from Trent Arnold, Sondi Bootle, Sarah Brown, Neal Masters and Gary Ogden. We also thank Greg Ivey, David Luketina, Gherd Masselink, Gary Kendrick, Pierre Horwitz and 4 anonymous reviewers for their valuable comments on the manuscript Centre for Water Research Report ED1230CO.

\section{LITERATURE CITED}

Aller RC (1984) Solute transport in bioturbated sediments: model artifacts. Trans Am Geophys Un 65:905-912

A.PHA (1989) Standard methods for the examination of water and wastewater, 17th edn. Am Public Health Assoc, Am Wat Wastewat Assoc, Washington, DC

Batchelor GK (1959) Small-scale variation of convected quantities like temperature in turbulent fluid. J Fluid Mech 5: $113-133$

Bolliger R, Brandl H, Hohener P, Hanselmann KW, Bachofen R (1992) Squeeze-water analysis for determination of microbial metabolism in lake sediments. Comparison of methods. Limnol Oceanogr 37:448-455

Dillon TM, Caldwell DR (1980) The Batchelor spectrum and dissipation in the upper ocean. J Geophys Res 85: $1910-1916$

Dugdale RC, Goering JJ (1967) Effect of new and regenerated forms of nitrogen in primary production. Limnol Oceanogr 12:196-206

Fischer HG, List EJ, Koh RCY, Imberger J, Brooks NH (1979) Mixing in inland and coastal waters. Academic Press, San Diego

Fredsoe J, Deigaard R (1994) Mechanics of coastal sediment transport. World Scientific, Singapore

Gabrielson JO, Lukatelich RJ (1985) Wind-related resuspension of sediments in the Peel-Harvey Estuarine System. Estuar Coast Shelf Sci 20:135-145

Glud RN, Forster S, Huettel M (1996) Influence of radial pressure gradients on solute transport in stirred benthic chambers. Mar Ecol Prog Ser 141:303-311

Grant WD, Madsen OS (1979) Combined wave and current interaction with a rough bottom. J Geophys Res 84 $1797-1808$

Grant WD, Madsen OS, Glenn SM (1984) Bottom stress estimates and their prediction on the Northern Californian Continental Shelf during CODE-1: the importance of wave-current interactions. J Phys Oceanogr 14:506-527

Hammond D, Fuller C, Harmon D, Hartman B, Korosee M Miller L, Rea R, Warren S, Berelson W, Hager S (1985) Benthic fluxes in San Francisco Bay. Hydrobiologia 129 $69-90$

Harris G, Batley G, Fox D, Hall D, Jernakoff $P$, Molloy $R$, Murray B, Newell B, Parslow J, Skyring G, Walker S (1996) Port Phillip Bay environmental study final report. CSIRO, Canberra

Huettel M, Gust G (1992) Impact of bioroughness on interfacial solute exchange in permeable sediments. Mar Ecol Prog Ser 89:253-267

Editorial responsibility: Otto Kinne (Editor),

Oldendorf/Luhe, Germany
Huntley DA (1988) A modified inertial dissipation method for estimating seabed stresses at low Reynolds numbers, with application to wave/current boundary layer measurements. J Phys Oceanogr 18:339-346

Imberger J, Boashash B (1986) Application of the WignerVille distribution to temperature gradient microstructure: a new technique to study small-scale variations. J Phys Oceanogr 16:1997-2012

Imberger J, Ivey GN (1991) On the nature of turbulence in a stratified fluid. Part 2: Application to lakes. J Phys Oceanogr 21:659-680

Ivey GN, Imberger $J$ (1991) On the nature of turbulence in a stratified fluid. Part 1: The energetics of mixing. J Phys Oceanogr 21:650-658

Jørgensen BB, Revsbech NP (1985) Diffusive boundary layers and the oxygen uptake of sediments and detritus. Limnol Oceanogr 30:111-122

MacIntyre S (1993) Vertical mixing in a shallow eutrophic lake: possible consequences for the light climate of phytoplankton. Limnol Oceanogr 38:798-817

Mack SA (1985) Two-dimensional measurements of ocean microstructure; the role of double diffusion. J Phys Oceanogr 15:1581-1604

Malan DE, McLachlan A (1991) In situ benthic oxygen fluxes in a nearshore coastal marine system: a new approach to quantify the effect of wave action. Mar Ecol Prog Ser 83 $69-81$

Masselink G (1996) Sea breeze activity and its effect on coastal processes near Perth, Western Australia. J R Soc West Aust 79:199-205

Masselink G, Pattiaratchi C (1998) The effect of sea breeze on beach morphology, surf zone hydrodynamics and sediment resuspension. J Mar Geol 146:115-135

MWRA (1992) Sediment denitrification in Boston Harbor. Environmental Quality Division Report 92-2. Massachusetts Water Resources Authority, Boston

Oldham CE (1994) A fast-response oxygen sensor for use on finescale and microstructure CTD profilers. Limnol Oceanogr 39:1959-1966

Riedl RJ, Huang N, Machan R (1972) The subtidal pump: a mechanism of interstitial water exchange by wave action. Mar Biol 13:210-221

Simmons GM (1992) Importance of submarine groundwater discharge (SGWD) and seawater cycling to material flux across sediment/water interfaces in marine environments. Mar Ecol Prog Ser 84:173-184

Sondergaard M, Kristensen P, Jeppesen E (1992) Phosphorus release from resuspended sediment in the shallow and wind-exposed Lake Arreso, Denmark. Hydrobiologia 228: 91-99

Terray EA, Donelan MA, Agrawal YC, Drennan WM, Kahma KK, Williams A.J, Hwang PA, Kitaigorodskii SA (1996) Estimates of kinetic energy dissipation under breaking waves. J Phys Oceanogr 26:792-807

Thompson PA, Hosja W (1996) Nutrient limitation in phytoplankton in the Upper Swan River Estuary, Western Australia. Mar Freshw Res 47:659-667

van Rijn LC (1985) Sediment transport. Part 1: Bed load transport. J Hydraul Eng 110:1431-1456

Submitted: February 24, 1998; Accepted: March 16, 1999 Proofs received from author(s): June 23, 1999 